(1.) Jambura Physics Journal

\title{
SYNTHESIS OF CARBON DOTS (CDS) AND DETERMINATION OF OPTICAL GAP ENERGY WITH TAUC PLOT METHOD
}

\author{
Jumardin $^{1}{ }^{*}$ Akhiruddin Maddu' ${ }^{2}$, Koekoeh Santoso ${ }^{3}$, and Isnaeni ${ }^{4}$ \\ ${ }^{1}$ Department of Physics, Science and Technology of Faculty, Islamic State University of Alauddin \\ Makassar, Jalan Sultan Alauddin No. 63, South Sulawesi, Gowa 92113, Indonesia \\ 2 Department of Physics, Mathematic and Natural Science of Faculty, IPB University, Jalan Raya \\ Dramaga, West Java, Bogor 16680, Indonesia \\ ${ }^{3}$ Departement of Anatomy, Physiology and Pharmacology, Veterinary of Faculty, IPB University, Jalan. \\ Raya Dramaga, West Java, Bogor 16680, Indonesia \\ ${ }^{4}$ Research Center for Physics, Indonesian Institute of Sciences, Riset Rd. Building 442, Puspiptek, South \\ Tangerang, Banten 15314, Indonesia \\ *Email: jumardin.jumardin@uin-alauddin.ac.id
}

Received: 15 July 2021. Accepted: 09 September 2021. Published: 25 October 2021

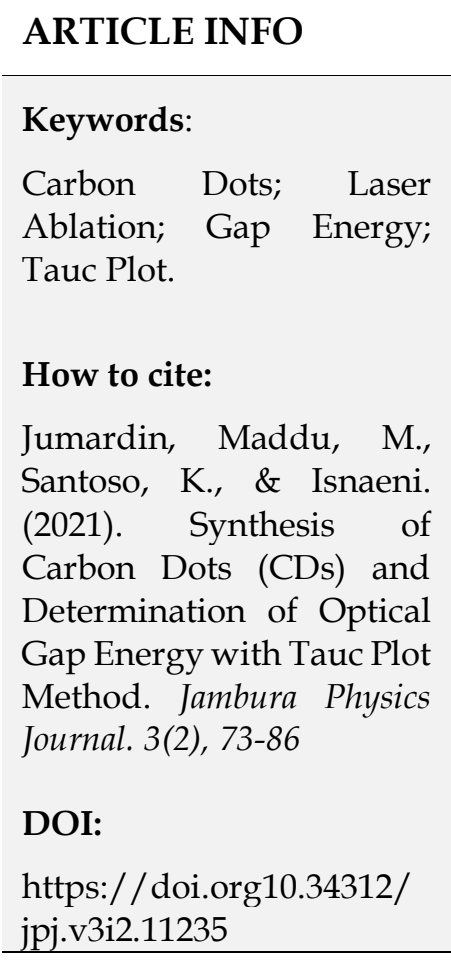

\begin{abstract}
Carbon Dots (CDs) which have been synthesized using the laser ablation method show the presence of UV-Vis absorption in the wavelength range of $303 \mathrm{~nm}$ to $333 \mathrm{~nm}$ for absorbance and $495 \mathrm{~nm}$ to $503 \mathrm{~nm}$ for fluorescence. Changes in the time duration 1, 2, 3 hours of CDs resulted in changes in the optical energy gap. The optical energy gap values are distinguished by the type of indirect transition ( $n=2)$ is $3.40 \mathrm{eV}$ ( 1 hour), $3.15 \mathrm{eV}$ ( 2 hour), $2.85 \mathrm{eV}$ (3 hour) and direct transition ( $n=1 / 2)$ is $2.58 \mathrm{eV}$ ( 1 hour), $2.31 \mathrm{eV}$ ( 2 hour), $1.70 \mathrm{eV}$ (1 hour).
\end{abstract}

\section{Introduction}

Carbon is a material that is easily obtained from various sources of organic life so that its development in the field of material engineering is very popular, such as 3- 
Jumardin et al./ Jambura Physics Journal (2021) Vol. 3(2): 73-86

dimensional graphite (Belenkov \& Ali-Pasha, 2011), 2-dimensional graphene and graphene oxide (Klintenberg et al., 2009), 1-dimensional carbon nanotubes, to carbon nanomaterials (Ahmadi et al., 2008). In general, carbon is a black material, has low solubility in water and has low fluorescence. In contrast to carbon nanodots (CDs) they contain carboxylic acids on their surface and can cause higher solubility in water so that they can be functionalized against organic, polymeric, inorganic, and biological materials (Baker et al., 2010). CDs are defined as carbon nanoparticle-sized materials that have zero dimensions with a size of 2-10 $\mathrm{nm}$ and has the characteristics of heavy metal based on quantum dots (Dave, 2020). The discovery of new materials from carbon in the form of carbon nanodots (CDs) is a topic that will be widely studied in the world of science because, in terms of the unique size and benefits produced, CDs have strong photoluminescence properties.

Fundamental research and applications of carbon-based materials have always been popular in chemistry, materials, and other interdisciplinary fields. However, macroscopic carbon materials do not have the appropriate bandgap energy, making them difficult to be effective fluorescence materials. The topic of Carbon Dots (CDs) has been around for decades this year and is a very promising area of materials research. CDs are a new model of carbon atoms with a particle size of less than $10 \mathrm{~nm}$ (Lim et al., 2015). CDs also present interesting fluorescent properties (Liu et al., 2016), low toxicity (Wang et al., 2013), good water solubility (Bhatt et al., 2020), good biocompatibility (Emam et al., 2017), has many types of functional groups such as amino, hydroxyl and carboxyl compounds (Ding et al., 2020), high stability (Basu et al., 2015) and electron mobility (Zhang et al., 2018). Making CDs can use materials from nature such as plants that have environmentally friendly properties, are cheap and easy to find and are available around our environment. Therefore, the fluorescence of CDs has great potential for application in photocatalysis (Peng et al., 2020), bioimaging (Dias et al., 2019), drug delivery systems (Sun et al., 2020), and other related fields. Very small CDs with large surface-to-volume ratios are expected to improve their performance in sensing (Sun et al., 2017) and catalytic applications (Hutton et al., 2017).

Synthesis of carbon nanoparticles obtained by laser ablation method onto carbon targets immersed in water is a method that can be optimized to produce carbon nanoparticles with a size of about $100 \mathrm{~nm}$ (Goncalves et al., 2010). The fluorescence properties of CDs that have been synthesized by the laser ablation method in colloidal form is an interesting process because it has many applications. However, unlike the CDs produced by the hydrothermal method, the CDs synthesized by the laser ablation method were never separated by the dialysis form. But what distinguishes it is the result of the synthesis and the identification of the source of the fluorescence properties (Kaczmarek et al., 2021).

Tea dregs are leftovers from tea that has undergone a dissolution process with water so that the remaining fibres are more dominant in the form of insoluble fibre. Tea waste containing cellulose (37\%), hemicellulose and lignin (14\%), and polyphenols $(25 \%)$ (Bajpai \& Jain, 2010). Dried tea dregs are easily found in various waste disposal locations. The development of research related to the use of tea dregs for CDs has been carried out by several researchers. The use of tea dregs and peanut shells in the concept of waste utilization and environmental protection shows good CDs stability, emits a strong blue fluorescence, is stable under ultraviolet light excitation and has many 
Jumardin et al./ Jambura Physics Journal (2021) Vol. 3(2): 73-86

hydrophilic functional groups on its surface (Zhu et al., 2019). Tea grounds that have been used as precursors for CDs have been reported in one study. The results of the electrostatic interaction of positive charges on chitosan and negative charges on CDs made from tea were used for the manufacture of nanocomposite hydrogel films based on CDs-chitosan which had stable and strong properties (Konwar et al., 2015).

The laser ablation process was induced in acetone with laser pulses of 1064, 532, and $355 \mathrm{~nm}$ at different irradiation times (Isnaeni et al., 2017). Synthesis of the nanoparticle structure of fluorescent CDs obtained by laser ablation of solid carbon targets in colloidal form has been reported by several studies (Reyes et al., 2016). The Tauc Plot method is a method of determining the optical band gap by looking at a linear graph of the relationship $\mathrm{E}(\mathrm{eV})$ on the $\mathrm{x}$-axis and (ahv) $\mathrm{m}-1 \mathrm{y}$-axis. The determination of the energy gap value is determined for 2 possible types of transitions, namely direct transitions and indirect transitions based on calculations using the Tauc Plot method (Abed et al., 2020). The synthesis of CDs using wastepaper has been successfully carried out and the addition of synthesis time affects the absorption of a wider spectrum and lower energy gap (Fadlan et al., 2017). For electron transition, minimum energy is required. Therefore, the energy gap of CDs is controlled by the heating temperature. The energy change of CDs has been determined by the Tauc Plot method (Aji et al., 2017).

\section{Method}

The initial stage is the manufacture of carbon material 250 grams of tea dregs is put into a carbonization device (Furnace) with an initial temperature of $25^{\circ} \mathrm{C}$ to a final temperature of $900^{\circ} \mathrm{C}$ at a temperature rise rate of $600^{\circ} \mathrm{C} /$ hour (Vinsiah et al., 2014).

The carbon was crushed using a mortar to a powder size before being treated with laser ablation. The equipment used is a Pulse Laser Type Q Switch Nd: YAG Laser Model Q Smart 850, digital scales, micropipettes, magnetic stirrer, stopwatches, thermal furnaces, measuring cups and measuring bottles. The materials used are Toluene $\left(\mathrm{CH}_{7} \mathrm{H}_{8} \mathrm{M} . W 92.14 \mathrm{gr} / \mathrm{mol}\right)$ and carbon from Goalpara brand tea dregs in the

(1)

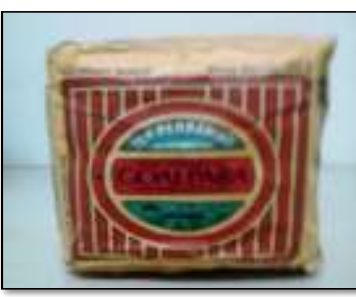

Goalpara brand tea

(4)

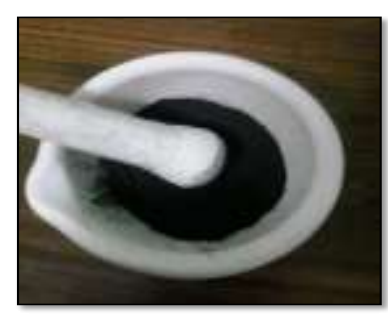

Carbon from tea
(2)

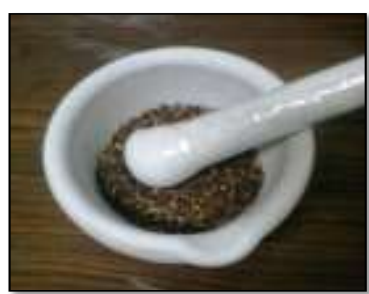

Tea powder

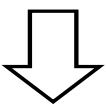

(3)

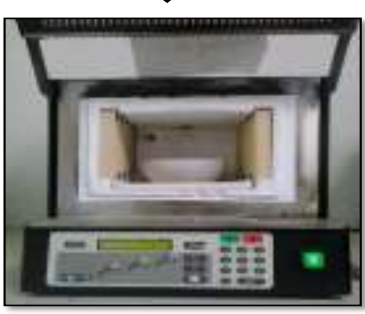

Carbonization process

Figure 1. Carbon material manufacturing scheme. 


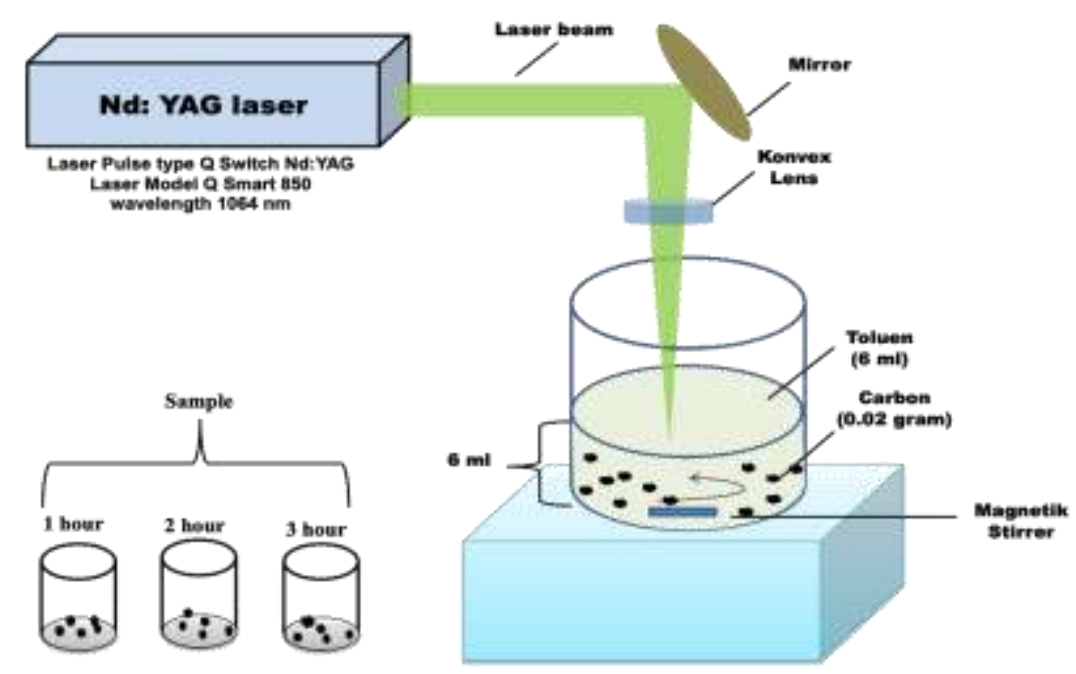

Figure 2. Schematic of CDs fabrication by laser ablation method.

carbonization process. The laser ablation method uses a wavelength of $1064 \mathrm{~nm}$ and a frequency of $10 \mathrm{~Hz}$ (Li et al., 2011). The pulse width used is $\pm 6 \mathrm{nsec}$ at an energy level of $60 \mathrm{~mJ}$. The CDs fabrication method uses a duration control of 1, 2, and 3 hours. The laser beam is focused on a colloidal carbon material with a carbon weight concentration of 0.02 grams in $6 \mathrm{ml}$ of toluene solvent. Using a lens and mirror to focus the laser light precisely on the carbon material in the bottle and a magnetic stirrer to homogenize the carbon particles with the toluene molecules.

Measurement of optical properties was carried out using a UV-Vis Spectro photometer and a laser Spectro fluorometer $405 \mathrm{~nm} \pm 10 \mathrm{~nm}$ (Ocean Optic ${ }^{\mathrm{TM}} 4000$ ), micropipette, UV lamp, halogen lamp and optical cable. This measurement was carried out to determine the luminescence and peak intensity of the CDs wavelength from laser ablation samples 1, 2, and 3 hours. The materials used in the measurements were samples of CDs (1, 2, 3 hours) laser ablation results, cuvette bottles (Quartz cuvette $3.8 \mathrm{ml})$. Optical properties transmittance is measured based on the intensity of the absorbance of CDs. A total of $2 \mathrm{ml}$ of CDs dissolved in toluene was inserted into a cuvette which was connected directly to the spectrophotometer via an optical cable with a halogen lamp as a light source. The measurement of the optical properties of fluorescence was carried out by firing a laser beam of $405 \pm 10 \mathrm{~nm}$ towards the sample through an optical cable in an upright position.

Morphological analysis of CDs was characterized by using TEM (Transmission Electron Microscopy, FEI Tecnai G2 20S Twin) 200 kV. The CDs samples tested were the result of laser ablation which had higher intensity and wavelength peaks. The CDs in the toluene solution were transferred as much as $1 \mathrm{mg} / \mathrm{ml}$ to the measurement container. Then dried for a few minutes and after drying the CDs were inserted into the TEM spot or holder to take morphological images with a magnification of $500 \mathrm{~nm}$ and $50 \mathrm{~nm}$. Analysis of the particle size distribution of CDs was carried out using image-J software (Kurniawan et al., 2011).

The energy level indicates the difference of each CDs that has been synthesized by the laser ablation method. Energy is calculated based on absorbance (excitation) and fluorescence (emission) wavelengths using equation (1), where $\mathrm{h}$ is Planck's constant $\left(6.62 \times 10^{-34} \mathrm{Js}\right), \mathrm{c}$ is the speed of light $\left(3 \times 10^{8} \mathrm{~m} / \mathrm{s}\right)$ and is the wavelength $(\mathrm{nm})$. 


$$
\mathrm{E}=\frac{\mathrm{h} \cdot \mathrm{c}}{\lambda}
$$

The determination of the gap energy $(\mathrm{Eg})$ of CDs is carried out fundamentally, namely the transition from absorbance and transmittance. Direct and indirect transitions can use equation (2) (Ali., 2011). Where A is the optical constant, is the absorbance coefficient $\left(\mathrm{cm}^{-1}\right)$, hv is the photon energy, $\mathrm{Eg}$ is the gap energy and $\mathrm{n}$ is the transition value which depends on the type of transition (direct transition, $n=1 / 2$ and indirect transition, $\mathrm{n}=2$ ). The absorption coefficient $(\mathrm{a})$ is calculated using equation (3). Where $\mathrm{a}$ is the absorbance value and $\mathrm{d}$ is the diameter of the cuvette thickness (cm). The optical band gap energy is determined using the equation (Oo et al., 2012):

$$
\begin{gathered}
(\alpha h v)^{\frac{1}{n}}=A(h v-E g) \\
\alpha=\frac{2.303 \mathrm{a}}{\mathrm{d}}
\end{gathered}
$$

The bandgap energy (Eg) was calculated based on the values obtained from the absorption coefficient and energy (hv) of each sample CDs. The optical band gap energy is defined as the difference between the valence band and the conduction band. To determine the optical band gap energy, first, convert the wavelength into photon energy. Each wavelength has its absorption value, the absorption value is then multiplied by a predetermined photon energy value. Next, a graph of the relationship between photon energy (hv) and ( $\mathrm{h}$ h) is made. Determination of the optical bandgap energy can be done using the Taucs' plot method. The Taucs' plot method is a method of determining the optical gap by extrapolating from the graph of the relationship between (hv) and ( $\alpha$ hv) to intersect the energy axis so that the optical band gap value is obtained (Effendi, 2012).

Where $\alpha$ is the absorption coefficient, hv is the energy of the incident photon, $\mathrm{A}$ is the electronic transition constant, $\mathrm{n}$ is the type of electronic transition, and Eopt is the optical band gap. The value of $n$ is equal to for a direct transition, while for an indirect transition, the value of $\mathrm{n}$ is equal to 2 . Therefore, the optical band gap energy can be determined by referring to equation (3) and we get equation. Based on equation (2), the graph made for the determination of the optical band gap energy using the Taucs' plot method is a graph of the relationship between $(h v)$ and $(\alpha h v)^{1 / 2}$. The optical band gap energy value is the correspondence between the linear extrapolation region with $(\alpha h v)=0$.

\section{Result and Discussion}

The optical properties of CDs based on experimental observations of UV Vis spectro photometer and fluorescence can be seen in table 1 . The results of the measurement of the optical properties of CDs in colloidal form can absorb the UV spectrum at peak wavelengths of $305 \mathrm{~nm}, 322 \mathrm{~nm}$, and $333 \mathrm{~nm}$, while the peak wavelengths of fluorescence produced are $495 \mathrm{~nm}, 500 \mathrm{~nm}$ and $503 \mathrm{~nm}$ at different laser ablation durations.

The comparison between these energies affects the passivation of CDs on the surface to produce a higher photoluminescence intensity (Thongpool et al., 2012). It can be seen in figure 3 that the blue glow of CDs 1, 2, and 3 hours is visible. 


\begin{tabular}{ccccc}
\hline \multirow{2}{*}{ Table 1. Measurement of optical properties of CDs } \\
\multirow{2}{*}{ No } & Optical Properties & \multicolumn{3}{c}{ Peak Wavelength (nm), $\boldsymbol{\lambda}$} \\
\cline { 3 - 5 } & & $\mathbf{1}$ hour & 2 hour & 3 hour \\
\hline 1 & Absorbance & 305 & 322 & 333 \\
2 & Flourescence & 495 & 500 & 503 \\
\hline
\end{tabular}
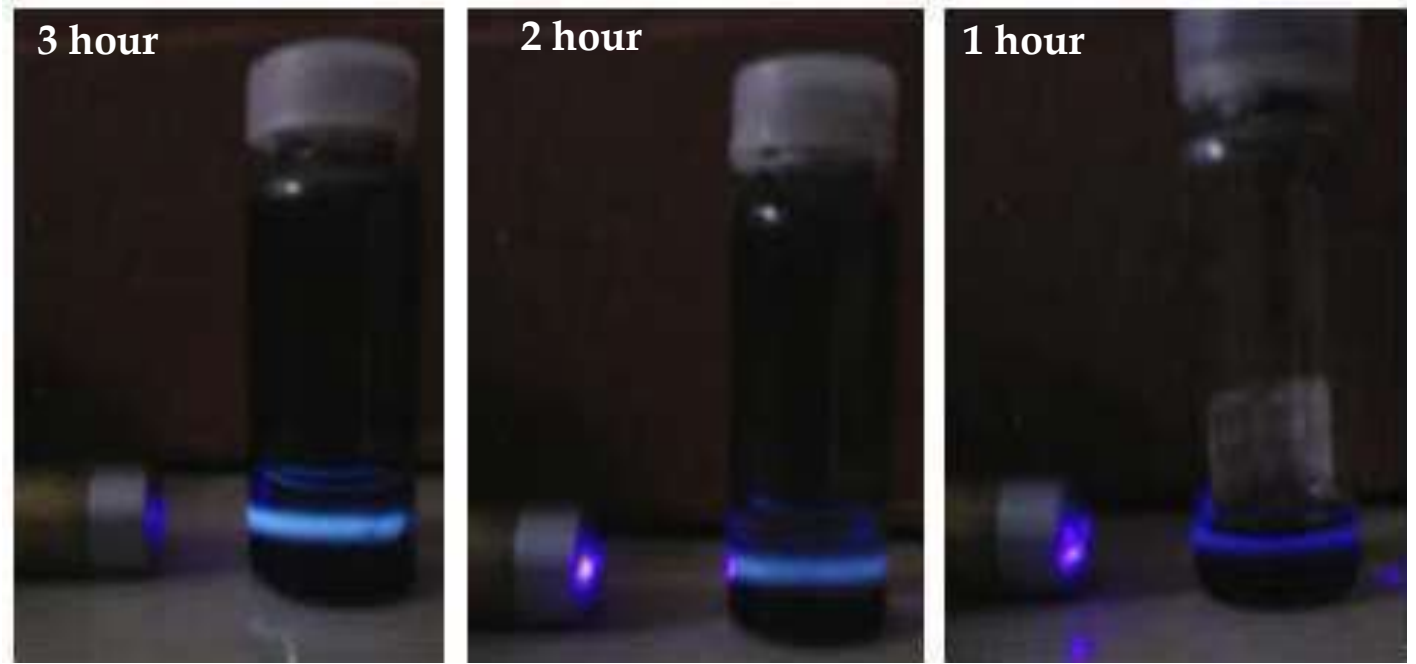

Figure 3. Blue light luminescence CDs (1, 2, and 3) hours.

Based on research conducted by Sun et al., (2006) that the luminescence events that occur undergo passivation on the surface caused by the presence of surface energy traps that cause emission stability. The three wavelength peaks of CDs show that the edge of the absorption band shifts to the longer wavelength region so that electrons are excited from the valence energy to the conduction spectrum. Similar studies conducted by several researchers described the results of shifting peak wavelengths based on differences in laser ablation time of material samples (Ajimsha et al., 2008).

The absorption region of image 4 (a) in the ultraviolet shifts its wavelength peak with each increase in laser ablation time and results in changes in energy of $4.05 \mathrm{eV}$ ( 1 hour), $3.84 \mathrm{eV}$ ( 2 hours) and $3.71 \mathrm{eV}$ ( 3 hours) seen in figure 4 (b). This difference indicates that there are optical absorption at ultraviolet wavelengths so that the three-wavelength peaks indicate an electronic transition from $\pi \rightarrow \pi^{*}$ as well as conjugation in the CDs structure (Qu et al., 2012). This also shows the stability of the particle before falling from a higher energy level so that the difference in the absorption area indicates the presence of different molecular groups. Molecules will be excited from the HOMO (Highest Occupied Molecular Orbital) state to the LUMO (Lowest Unoccupied Moleculer Orbital) state when interacting with photons.

Based on figure 5 (a) the fluorescence intensity changes due to the different duration of laser ablation so that nergy changes are $2.51 \mathrm{eV}$ (1 hour), $2.47 \mathrm{eV}$ (2 hours) and $2.46 \mathrm{eV}$ ( 3 hours). It has been described that the emission produced by photoluminescence of nanoparticles from a passivated surface is caused by recombination of electron-hole pair radiation (Wilson et al., 1993). 

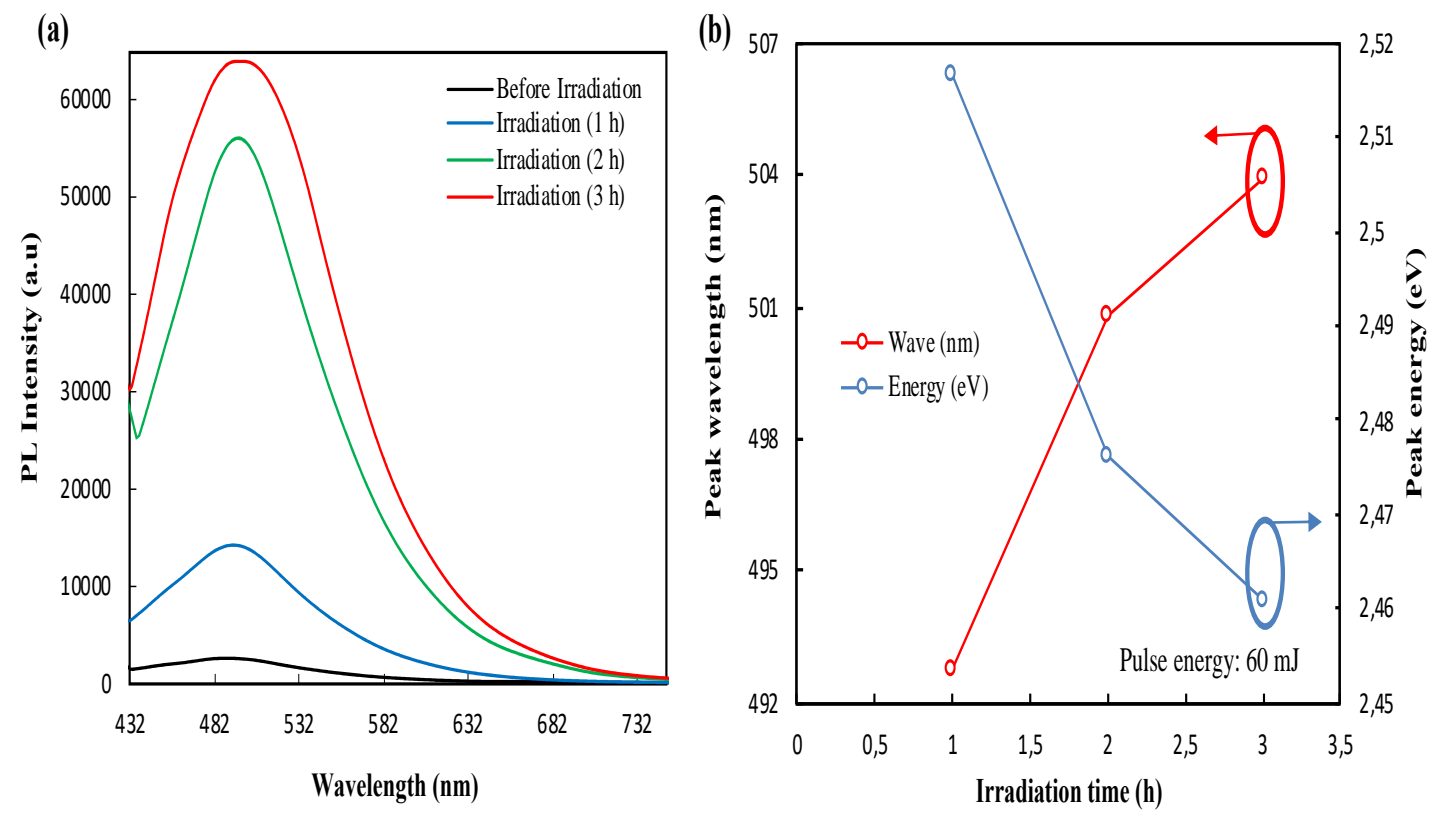

Figure 4. (a) The correlation curve of fluorescence intensity to wavelength and (b) The curve of the relationship of laser ablation time to the peak wavelength and peak energy.

The morphology of CDs was characterized by using Transmission Electron Microscopy (TEM). Observations were made at a magnification scale of $500 \mathrm{~nm}$ and $50 \mathrm{~nm}$. Based on the observations on this scale, the CDs images are obtained in an inhomogeneous form as shown in Figures 6 (a) and (b).

(a)

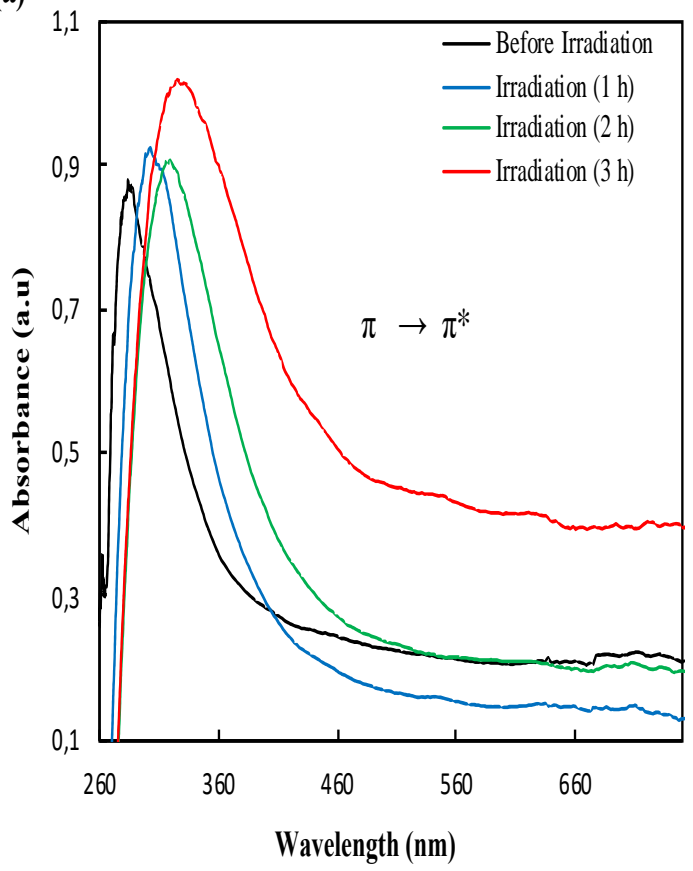

(b)

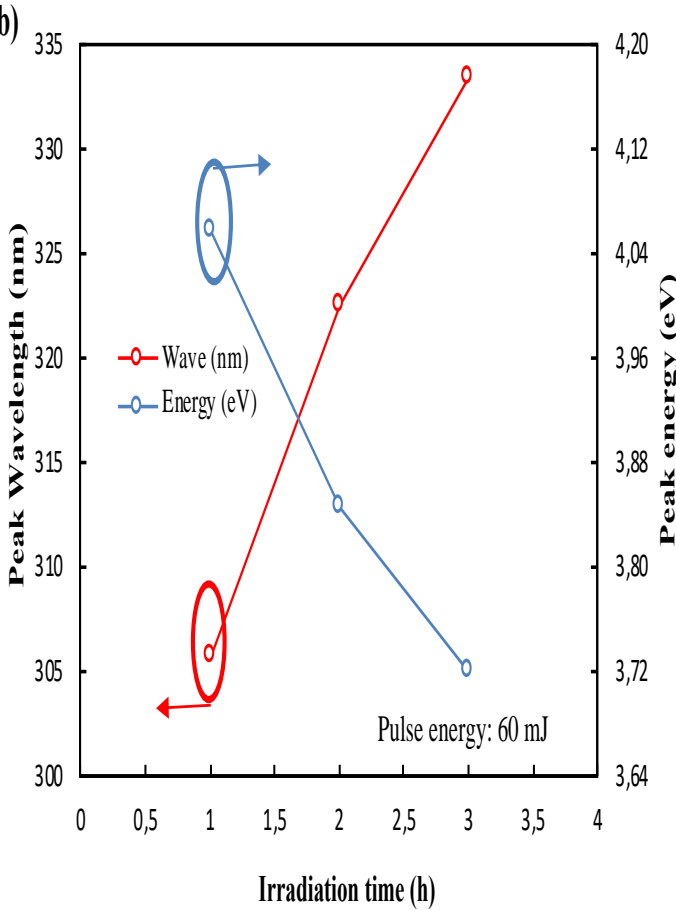

Figure 5. (a) The curve of the relationship between the absorbance intensity and the wavelength and (b) The curve of the relationship between the laser ablation time and the peak wavelength and energy. 


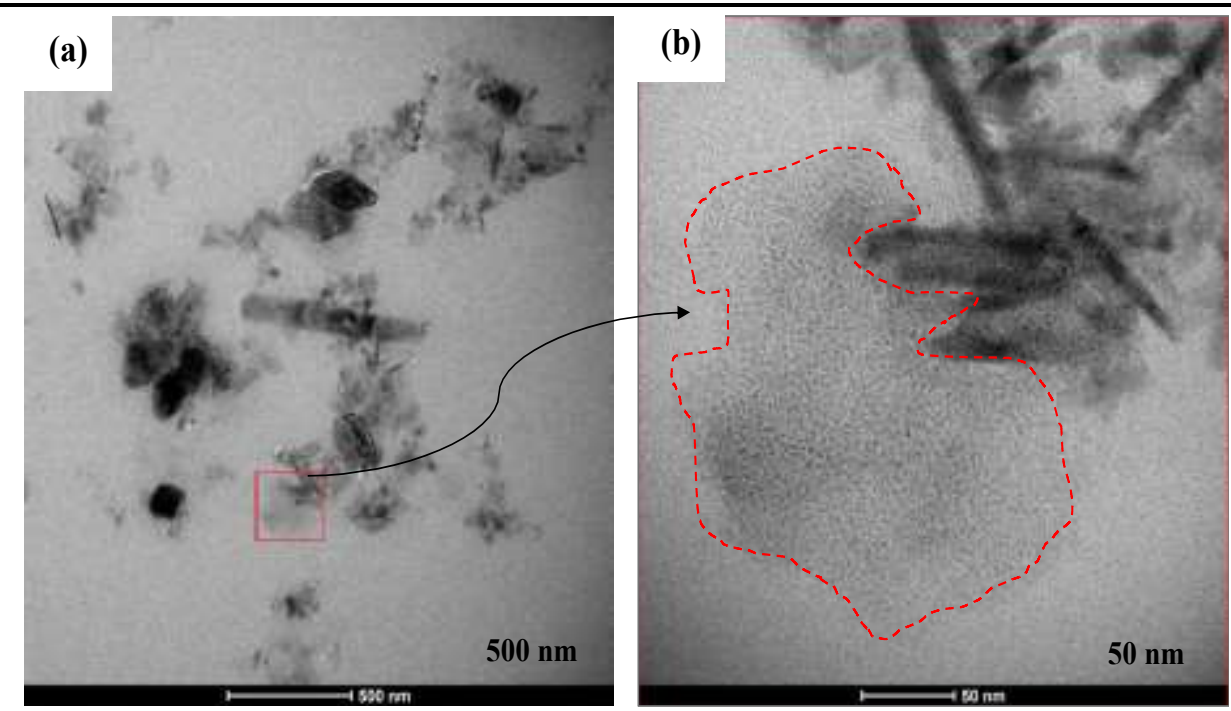

Figure 6. (a) and (b) morphology at $500 \mathrm{~nm}$ and $50 \mathrm{~nm}$ magnification scales.

The TEM characterization for CDs distributes an average diameter of less than $50 \mathrm{~nm}$ and shows a small spherical structure that can only be seen using the magnification scale of the TEM tool. Measurements on a $50 \mathrm{~nm}$ scale show CDs with an average diameter of (40-50) $\mathrm{nm}$.

This site is an analysis based on data processing for one object position at a magnification scale of $50 \mathrm{~nm}$ using ImageJ software (https://imagej.nih.gov/ij/) through the Thresholding process and outline drawing figure 7 (a). The most dominant sample distribution is $40 \mathrm{~nm}$ at the highest frequency percentage figure 7 (b). The same study using laser radiation pulse wavelengths of $1064 \mathrm{~nm}$ and $335 \mathrm{~nm}$ showed a very small diameter $(0.299 \mathrm{~nm})$ using HR-TEM (Vinod et al., 2014). Based on these results, CDs are spherical and evenly distributed particles with a diameter of 2-7 nm (Prasannan et al., 2013).

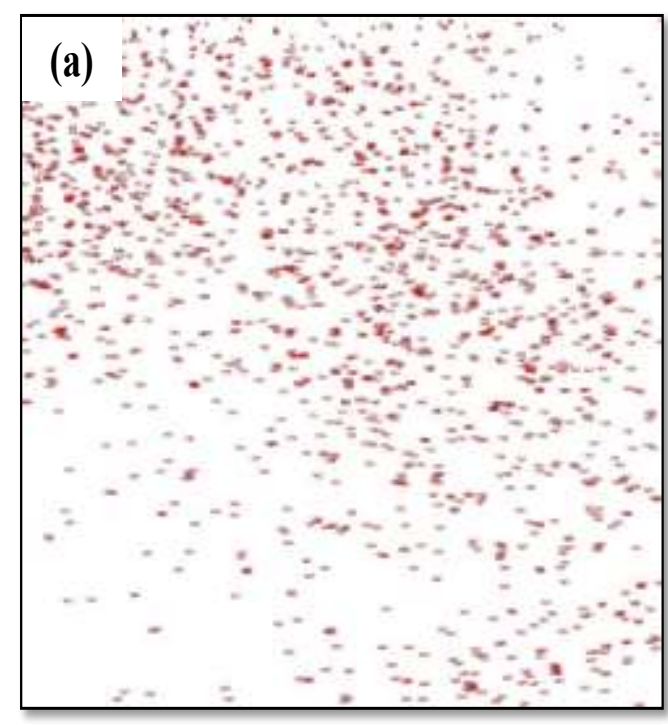

Threshold-ImageJ

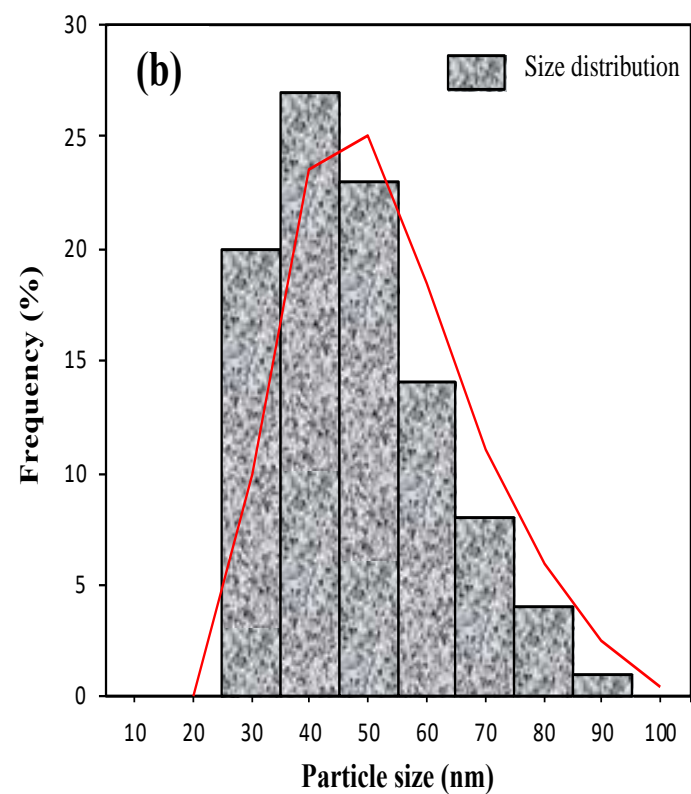

Figure 7. (a) Threshold-ImageJ sample image of CDs and (b) histogram of CDs size. 

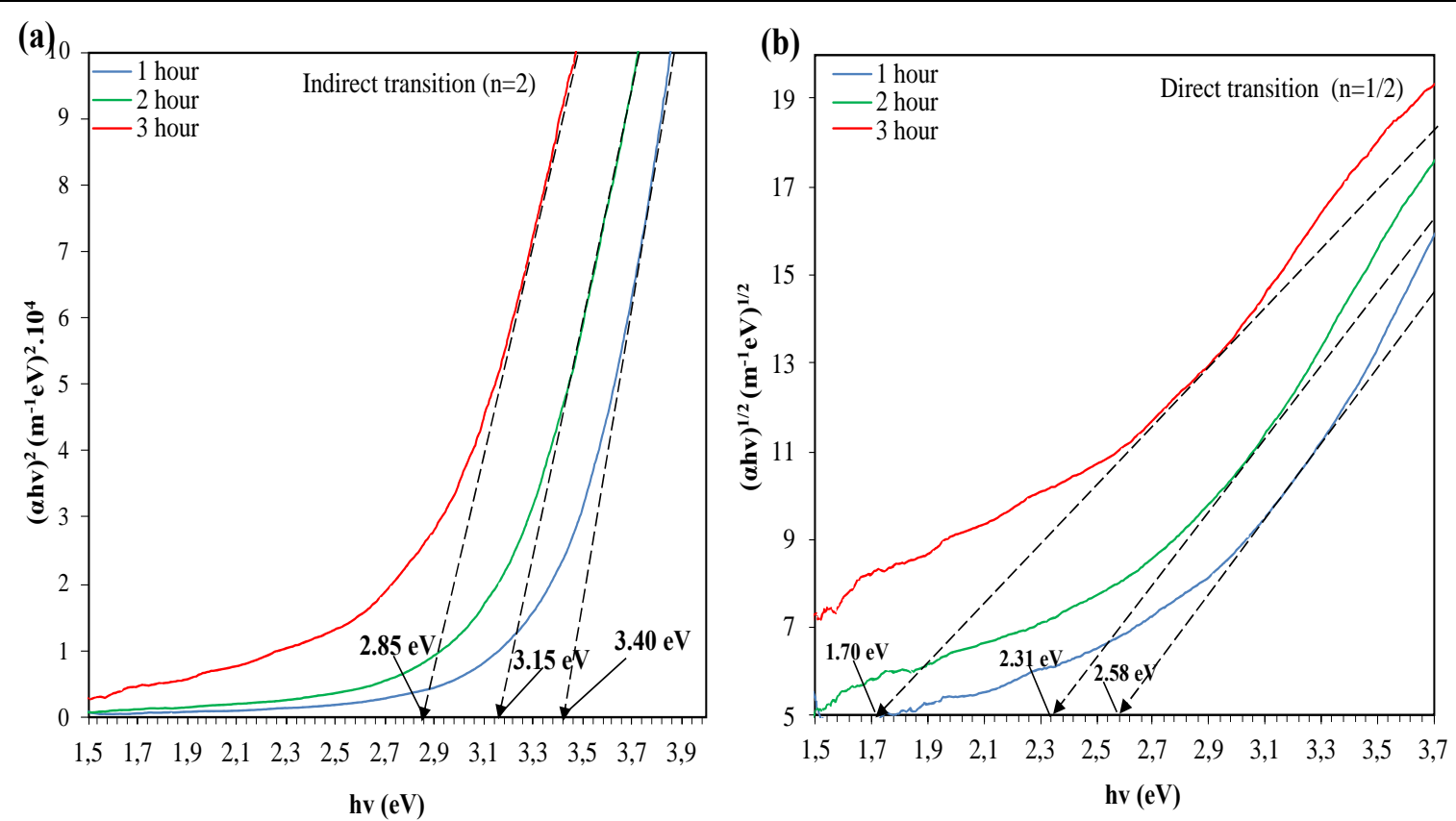

Figure 8. The plot of absorbance photon energy (hv) against $(\alpha h v)^{2}$ (a) direct transition and $(b)$ indirect transition.

The bandgap energy value (Eg) of CDs is highly dependent on the type of electronic transition. Figure $8(\mathrm{a})$ and (b) are two different types of transition where $(n=2)$ for the direct transition type and $(n=1 / 2)$ for the indirect transition type (Tauc. 1972). The bandgap energy (Eg) is determined based on the intersection of the linear section curve with the energy axis (hv). The $\mathrm{Eg}$ values for each direct transition sample are shown in Figure 8 (a) which are $3.40 \mathrm{eV}, 3.15 \mathrm{eV}$ and $2.85 \mathrm{eV}$. Meanwhile, the indirect transitions are $2.85 \mathrm{eV}, 2.31 \mathrm{eV}$ and $1.70 \mathrm{eV}$ (figure (b).

The Tauc Plot method is to draw extrapolations on the linear region of the relationship curve $(h v)$ as the abscissa and $(\alpha h v)$ as the ordinate until it intersects the energy axis. Figure 8 (a and b) shows the relationship between the energy gap $(h v)$ to the coefficient absorbed by the photon $(\alpha h v)$ as an ordinate to intersect the energy axis so that the energy gap value is obtained. The independent variable is represented by the $\mathrm{X}$-axis while the $\mathrm{Y}$-axis represents the dependent variable.

The energy gap values for all samples can be seen in Table 2. The Eg value is not much different from previous studies using laser ablation methods, namely 2.4 $\mathrm{eV}, 2.5 \mathrm{eV}$ and $2.6 \mathrm{eV}$ (Anikin et al., 2002). The result of the plot in Figure 8 is a function $(\alpha h v) 2$ which was developed using the Tauc's Plot method intersecting the hv axis on Eg. Based on these results, changes in the time of laser ablation on the synthesis and fabrication of CDs cause changes in bandgap energy (Eg).

Table 2. Value of energy gap CDs

\begin{tabular}{lll}
\multirow{2}{*}{ Time (hour) } & \multicolumn{2}{c}{ Energi Gap (eV) } \\
\cline { 2 - 3 } & Indirect Transition & Direct Transition \\
\hline 1 & 3.40 & 2.58 \\
2 & 3.15 & 2.31 \\
3 & 2.85 & 1.70 \\
\hline
\end{tabular}


When CDs absorb laser ablation energy longer, the Eg value gets smaller. This is caused by the change in the quantum value of the confinement which causes an increase in the kinetic energy of the illuminated quantum field so that Eg changes with changes in the particle size and absorption wavelength. The coefficient region $(\alpha)$ in the ultraviolet range shifted with each increase in laser ablation time of 312 $\mathrm{nm}$ (1 hour), $331 \mathrm{~nm}$ ( 2 hours) and $341 \mathrm{~nm}$ (3 hours). The difference in these values indicates the presence of optical absorption at ultraviolet wavelengths. The edge of the absorption band shifts to a region of greater wavelength or lower frequency so that the resulting Eg will be smaller.

\section{Conclusion}

Changes in bandgap energy (Eg) occur due to differences in the duration of laser ablation. The increase in ablation duration also causes a change in the wavelength of the ultraviolet absorption so that the energy gap (Eg) produced is getting smaller. The fluorescence emission and absorption shift to a larger wavelength due to the electronic transition. Changes in ablation time also indicate the value of Eg based on the type of transition, namely direct and indirect transitions. The particle size of CDs was normally distributed in an inhomogeneous form and morphologically in the form of small balls seen in the Transmition Electron Microscope measurements.

\section{References}

Abed, R., N., Al-Sahib, N., K., \& Khalifa, A., J., N. (2020). Energy Gap Demeanor for Carbon Doped with Chrome Nanoparticle to Increase Solar Energy Absorption. Journal of Progress Color, Colorants and Coatings, 13: 143-154.

Ahmadi, M. T., Ismail, R., Tan, M. L. P., \& Arora, V. K. (2008). The Ultimate Ballistic Drift Velocity in Carbon Nanotubes. Journal of Nanomaterials, 2008, 1-8. https://doi.org/10.1155/2008/769250.

Aji, M., P., Susanto, Wiguna, P., A., \& Sulhadi. (2017). Facile Synthesis of Luminescent Carbon Dots from Mangosteen Peel by Pyrolysis Method. Journal of Theoritical and Applied Physics, 11 (2): 119-126. DOI: 10.1007/s40094-0170250-3.

Ali., M., M. (2011). Characterization of ZnO Thin Films Grow by Chemical Bath Deposition. Journal of Basrah Research, ISSN-1817-2695. Vol. 37, No. 3A.

Ajimsha, R., S., Anoop, G., Aravind, A., \& Jayaraj, M., K. (2008). Luminescence from Surfactant-Free ZnO Quantum Dots Prepared by Laser Ablation in Liquid. Journal of Electrochemical and Solid-State Letters, 11 (2), K14. DOI: 10.1149/1.2820767.

Anikin, K., V., Melnik, N., N., Simakin, A., V., Hafeev, G., A., Voronov, V., \& Vitukhnovsky, A., G., (2002). Formation of ZnSe and CdS Quantum Dots via Laser Ablation in Liquids. Journal of Chemical Physics Letters, 366 (3-4): 357360. DOI: https:/ / doi.org/10.1016/S0009-2614(02)01534-8. 
Jumardin et al./ Jambura Physics Journal (2021) Vol. 3(2): 73-86

Basu, A., Suryawanshi, A., Kumawat, B., Dandi, A., Guin, D, \& Ogale, S., B. (2015). Starch (Tapioca) to Carbon Dots: An Efficient Green Approach to On-Off-On Photoluminescence Probe for Fluoride Ion Sensing. The Analyst, 140 (6): 18371841. DOI: 10.1039/C4AN02340D.

Bajpai, S. K., \& Jain, A. (2010). Removal of copper (II) from aqueous solution using spent tea leaves (STL) as a potential sorbent. 36(3), 8 .

Baker, S. N., \& Baker, G. A. (2010). Luminescent Carbon Nanodots: Emergent Nanolights. Angewandte Chemie International Edition, 49(38), 6726-6744. https://doi.org/10.1002/anie.200906623.

Bhatt, M., Bhatt, S., Vyas, G., Raval, I., H., Haldar, S., \& Paul, P. (2020). WaterDispersible Fluorescent Carbon Dots as Bioimaging Agents and Probes for $\mathrm{Hg}^{2+}$ and $\mathrm{Cu}^{2+}$ ions, ACS Aplied Nano Materoals, 3 (7): 7096-7104. DOI: https://doi.org/10.1021/acsanm.0c01426.

Belenkov, E. A., \& Ali-Pasha, V. A. (2011). 3D-graphite structure. Crystallography Reports, 56(1), 101-106. https://doi.org/10.1134/S1063774511010044.

Dave, P. Y. (2020). Carbon Dots: Zero-Dimensional Fluorescent Material. 10(1), 11.

Dias, C., Vasimalai, N., Sárria, M., P., Pinheiro, I., Boas, V., Peixoto, J., \& Espiña, B. (2019). Biocompatibility and Bioimaging Potential of Fruit-Based Carbon Dots. Nanomaterials, 9 (2): 199. DOI: 10.3390/nano9020199.

Ding, H., Li, X., H., Chen, X., B., Wei, J., S., Li, X., B., \& Xiong, H., M. (2020). Surface States of Carbon Dots and Their Influences on Luminescence. Journal of Applied Physics, 127 (23): 231101. DOI: 10.1063/1.5143819.

Effendi, M. (2012). Analisis Sifat Optik Lapisan Tipis TiO2 Doping Nitrogen yang Disiapkan dengan Metode Spin Coating. 4.

Emam, A., N., Loutfy, S., A., Mostafa, A., A., Awad, H., \& Mohamed, M., B. (2017). Cyto-toxicity, Biocompatibility and Cellular Response of Carbon DotsPlasmonic Based Nano- Hybrids for Bioimaging. RSC Advances, 7 (38): 2350223514. DOI: 10.1039/c7ra01423f.

Fadlan, A., Marwoto, P., Aji, M., P., Susanto, \& Iswari, R., S. (2017). Synthesis of Carbon Nanodots from Wastepaper with hydrothermal Method. International Conference on Engineering, Science and Nanotechnology 2016 (ICESNANO 2016), 1788, 030069-1-030069-6. DOI: 10.1063/1.4968322.

Goncalves, H., Jorge, P., A., S., Fernandes, J., R., A., \& Esteve da Silva, J., C., G. (2010). Hg (II) Sensing Based on Functionalized Carbon Dots Obtained by Direct Laser Ablation. Sensors and Actuators B: Chemical, 145 (2): 702-707. DOI: 10.1016/j.snb.2010.01.031. 
Hutton, G., A., M., Martindale, B., C., M., \& Reisner, E. (2017). Carbon Dots as Photosensitisers for Solar-Driven Catalysis. Chemical Society Reviews, 46 (20): 6111-6123. DOI: 10.1039/c7cs00235a.

Isnaeni, Hanna, M., Y., Pambudi, A., A., \& Murdaka, F., H. (2017). Influence of Ablation Wavelength and Time on Optical Properties of Laser Ablated Carbon Dots. The 6th International Conference on Theoretical and Applied Physics (The 6th ICTAP). DOI: https://doi.org/10.1063/1.4973079.

Kaczmarek, A., Hoffman, J., Morgiel, J., Moscicki, T., Stobinski, L., Szymanski, Z., \& Małolepszy, A. (2021). Luminescent Carbon Dots Synthesized by the Laser Ablation of Graphite in Polyethylenimine and Ethylenediamine. Materials, 14 (4): 729. DOI: https:// doi.org/10.3390/ma14040729.

Klintenberg, M., Lebègue, S., Ortiz, C., Sanyal, B., Fransson, J., \& Eriksson, O. (2009). Evolving properties of two-dimensional materials: From graphene to graphite. Journal of Physics: Condensed Matter, 21(33), 335502. https:/ / doi.org/10.1088/0953-8984/21/33/335502.

Kurniawan. C., Waluyo, T., B., \& Sebayang, P. (2011). Analis Ukuran Partikel Menggunakan Free Software Image-J. Seminar Nasional Fisika 2011. Pusat Penelitian Fisika-LIPI. ISSN 2088-4176.

Li, X., Wang, H., Shimizu, Y., Pyantenko, A., Kawaghuci, K., \& Koshizaki, N. (2011). Preparation of Carbon Quantum Dots with Tunable Photoluminesence by Rapid Laser Passivation in Ordinary Organic Solvent. Chemistry of Communication, 47 (3): 932-934. DOI: 10.1039/c0cc03552a.

Lim, S., Y., Shen, W., \& Gao, Z. (2015). Carbon Quantum Dots and Their Applications. Chemical Society Reviews, 44 (1): 362-381. DOI: 10.1039/C4CS00269E.

Liu, Y., Wanga, P., Shiral Fernando, K., A., LeCroy, G., E., Maimaiti, H., HarruffMiller, B., A., \& Suna, Y., P. (2016). Enhanced Fluorescence Properties of Carbon Dots in Polymer Films. Journal of Mater Chemistry C, 4 (29): 6967-6974. DOI: 10.1039/ C6TC01932C.

Oo, H. M., Mohamed-Kamari, H., \& Wan-Yusoff, W. M. D. (2012). Optical Properties of Bismuth Tellurite Based Glass. International Journal of Molecular Sciences, 13(4), 4623-4631. https:/ / doi.org/10.3390/ijms13044623

Peng, Z., Zhou, Y., Ji, C., Pardo, J., Mintz, K., J., Pandey, R., R., Chusuei, C., C., Graham, R., M., Yan, G., \& Leblanc, R., M. (2020). Facile Synthesis of “BoronDoped" Carbon Dots and Their Application in Visible-Light-Driven Photocatalytic Degradation of Organic Dyes. Nanomateials, 10 (8): 1560. DOI: 10.3390/nano10081560. 
Jumardin et al./ Jambura Physics Journal (2021) Vol. 3(2): 73-86

Prasannan, A., \& Imae, T. (2013). One-Pot Synthesis of Fluorescent Carbon Dotsfrom Orange Waste Peels. Industrial \& Engineering Chemistry Research, 52(44): 15673-15678. DOI: 10.1021/ie402421s.

Qu, S., Wang, X., Lu, Q., Liu, X., \& Wang, L. (2012). A Biocompatible Flourecent in Based on Water-Soluble Luminescent Carbon Nanodots. Angewandte Chemie, 124 (49): 12381-12384. DOI: 10.1002/ange.201206791.

Reyes, D., Camacho, M., Camacho, M., Mayorga, M., Weathers, D., Salamo, G., Wang, Z., \& Neogi, A. (2016). Nanoscale Research Letters 11 (1): 424. DOI: 10.1186/s11671-016-1638-8.

Sun, Y., Zheng, S., Liu, L., Kong, Y., Zhang, A., Xu, K., \& Han, C. (2020). The Cost-

Effective Preparation of Green Fluorescent Carbon Dots for Bioimaging and Enhanced Intracellular Drug Delivery. Nanoscale Research Letter, 15 (1): 55. DOI: https://doi.org/10.1186/s11671-020-3288-0.

Sun, X., \& Lei, Y. (2017). Fluorescent Carbon Dots and Their Sensing Applications. Journal of Trends in Analytical Chemistry, 89:163-180. DOI: httpd://dx.doi.org/10.1016/j.trac.2017.02.001.

Sun, Y., P., Zhou, B., Lin, Y., Wang, W., Fernando, K., A., S., Pathak, P., Meziani, M., J., Harruff, B., A., Wang, X., Wang, H., Luo, P., G., Yang, H., Kose, M., E., Chen, B., Veca, L., M., \& Xie, S., Y. (2006). Quantum-Sized Carbon Dots for Bright and Colorful Photoluminescence. Journal of the American Chemical Society, 128 (24): 7756-7757. DOI: 10.1021/ja062677d.

Tauc, J. (1972). State In the Gap. Journal on Crystal Sol, 8 (10): 569-585.

Thongpool, V., Asanithi, P., Limsuwan, P. (2012). Synthesis of Carbon Particles Using Laser Ablation in Ethanol. Procedia Engineering, 32: 1054-1060. DOI: DOI:10.1016/j.proeng.2012.02.054.

Wang, K., Gao, Z., Gao, G., Wo, Y., Wang, Y., Shen, G., \& Cui, D. (2013). Systematic Safety Evaluation on Photoluminescent Carbon Dots. Nanoscale Research Letters, 8 (1): 122. DOI: 10.1186/1556-276X-8-122.

Wilson, W., L., Szajowski, P., F., \& Brus, B., L. (1993). Quantum Confinement in SizeSelected Surface-Oxidized Silicon Nanocristals. Science, 262 (5137): 1242-1244. DOI: $10.1126 /$ science.262.5137.1242.

Zhu, J., Zhu, F., Yue, X., Chen, P., Sun, Y., Zhang, L., Mu, D., \& Ke, F. (2019). Waste Utilization of Synthetic Carbon Quantum Dots Based on Tea and Peanut Shell. Journal of Nanomaterials, 2019, 1-7. https:/ / doi.org/10.1155/2019/7965756

Vinsiah, R., Suharman, A., \& Desi. (2014). Pembuatan Karbon Aktif dari Cangkang Kulit Buah Karet (Hevea Brasilliensis). Pendidikan Kimia Universitas Sriwijaya (189-199). 
Jumardin et al./ Jambura Physics Journal (2021) Vol. 3(2): 73-86

Vinod, M., \& Gopchandra, K., G. (2014). Au, Ag, and Au: Ag Colloidal Nanoparticles Synthesized by Pulsed Laser Ablation as SERS Substrates. Progres in Natural Science: Materials International, 24 (6): 569-678. DOI: https://doi.org/10.1016/j.pnsc.2014.10.003.

Zhang, R., Zhao, M., Wang, Z., Wang, Z., Zhao, B., Miao, Y., Zhou, Y., Wang, H., Hao, Y., Chen, G., \& Zhu, F. (2018). Solution-Processable ZnO/Carbon Quantum Dots Electron Extraction Layer for Highly Efficient Polymer Solar Cells. ACS Applied Materials and Interfaces, 10 (5): 4895-4903. DOI: 10.1021/acsami.7b17969. 